\title{
Competencias de gobernanza regional: Alianza del Pacífico-Mercosur y Unasur-OEA - estrategias colombianas ${ }^{1}$
}

\section{Competitions on regional governance: Pacific Alliance-Mercosur and Unasur-OEA - Colombian strategies}

Laszlo Vladimir Palotas Kelen

\begin{abstract}
Resumen
Este artículo de reflexión analiza dos competencias de gobernanza regional, la competencia entre la Alianza del Pacífico (AP) y el Mercosur, y la competencia entre la Unasur y la OEA, explorando las estrategias colombianas. Mientras la AP, combinada con el transregionalismo de sus miembros, parecía prevalecer en la competencia con el Mercosur para surtir el modelo privilegiado de gobernanza económica regional, la Unasur no solo perdió la competencia con la OEA por ejercer el mandato de la gestión de seguridad en América del Sur, sino quedó amenazada de extinción. La competencia Unasur-OEA entre dos organizaciones anidadas- era mucho más intensa que la competencia AP-Mercosur, atenuada con esfuerzos de convergencia. Mientras la competencia Unasur-OEA emanaba de una búsqueda de autonomía suramericana, apoyada en el ascenso de Brasil (hasta 2013), la competencia AP-Mercosur abarcó la contestación institucional colombiana frente a su aspiración al liderazgo regional.
\end{abstract}

\section{Palabras clave}

Alianza del Pacífico, Mercosur, Unasur, OEA, transregionalismo, balanceo blando, contestación institucional, autonomía, aquiescencia.

\section{Códigos de clasificación JEL: F15, N76, F53}

\begin{abstract}
This essay analyzes two competitions on regional governance: the competition between the Pacific Alliance (PA) and Mercosur, and the competition between UNASUR and the OEA - exploring Colombian strategies. While the PA, combined with the cross-regionalism of its members, seemed to prevail in the competition with Mercosur to provide the preferred model of regional economic governance, Unasur not only lost the competition with the OEA for exercising the mandate of the security management in South America, but came under the threat of extinction. The Unasur-OEA competition -between two nested organizations- was much more intensive than the PA-Mercosur competition, attenuated with convergence efforts. While the Unasur-OEA competition emanated from a quest for South American autonomy, based on the rise of Brazil (up to 2013), the PA-Mercosur competition included institutional contestation by Colombia at Brazil's bid for regional leadership.
\end{abstract}

\section{Keywords}

Pacific Alliance, Mercosur, Unasur, OEA, cross-regionalism, soft balancing, institutional contestation, autonomy, acquiescence.

Artículo de reflexión

2 Universidad Santo Tomás Seccional Bucaramanga.Correo electrónico: donlaszlo1@gmail.com. Código ORCID: 0000-0003-2109-079X 


\section{Introducción}

Este artículo examina dos competencias de gobernanza regional: la competencia entre la Alianza del Pacífico (AP) y el Mercado Común del Sur (Mercosur), y la competencia entre la Unión de Naciones Suramericanas (Unasur) y la Organización de Estados Americanos (OEA), indagando: ¿Cuál es el objeto de estas competencias?, ¿cómo se conectan con los balanceos institucionales y los complejos de gobernanza regionales?, ¿cuáles eran las estrategias de Colombia en estas competencias?

La competencia AP-Mercosur se ha librado por proveer el modelo privilegiado de gobernanza económica regional, mientras la competencia Unasur-OEA se desplegaba por ejercer el mandato exclusivo de la gestión de seguridad en América del Sur.

La competencia Unasur-OEA emanaba de una búsqueda de autonomía suramericana, apoyada en el ascenso de Brasil (hasta 2013), mientras la competencia AP-Mercosur abarcó la contestación institucional colombiana frente a su aspiración al liderazgo regional.

La Unasur compitió con la OEA, la organización central del (conflictivo) complejo hemisférico de gobernanza. Sin embargo, la AP, que incorporó a México, también transgredió al (cooperativo) complejo suramericano.

La desarticulación del complejo suramericano (apoyado en la Unasur como organización central) se aceleró con la vuelta de Argentina y Brasil a la verticalidad Norte. Los dos grandes se unieron a los miembros de la AP (México, Colombia, Chile, Perú ), socios importantes de EE. UU. en América Latina, aislando al gobierno venezolano que se asoció con China y Rusia.

El conflicto geopolítico en torno a Venezuela atravesó los tres complejos regionales de gobernanza en las Américas, dividiendo sus organizaciones claves: el Mercosur y la Unasur, la Celac ${ }^{3}$ y la OEA.

En cuanto a Colombia, de las estrategias comerciales, había aplicado el regionalismo cerrado del Pacto Andino (PA), ${ }^{4}$ y participó en la negociación del ALCA en el marco de la Comunidad Andina (CAN), bajo el regionalismo abierto. ${ }^{5}$ Incluso

3 Comunidad de Estados Latinoamericanos y Caribeños: creada en 2010 como sucesora del Grupo de Río, se ha empeñado en establecer un espacio para el diálogo y la cooperación entre todos los países de América Latina y el Caribe, así como entre ellos y la Unión Europea, China u otros interlocutores extrarregionales.

4 Regionalismo cerrado: extensión subregional de la política de industrialización por sustitución de importaciones. PA: desconectar la subregión temporalmente de economía mundial para construir base industrial-técnica. Muy alto arancel externo común. Planeación para repartir entre los miembros las nuevas industrias que sustituirán las importaciones. Gran participación estatal en sectores estratégicos. Decisión 24 para restringir la inversión extranjera.

5 Regionalismo abierto: la inserción de regiones integradas en la economía global. En boga en los 90, era uno de los pilares del regionalismo estratégico, junto con el "nuevo regionalismo". La Cepal recomendó formar el mercado ampliado, no tanto para derivar beneficios directos del comercio entre los socios, sino como una estrategia extravertida para insertarse en mejores condiciones en la economía mundial. Con esa idea se fundó el Mercosur y se reformaron otros esquemas con vocación de unión aduanera (Garzón y Prieto 2017). 
el Grupo de los Tres (G3) era un esquema plurilateral (Garzón y Prieto, 2017) ${ }^{6}$. Colombia solo emprendió la vía bilateral, cuando cayó el ALCA. La firma del TLC profundo con EE. UU. la llevó al transregionalismo, que complementaría con la conformación de la AP.

En seguridad regional, Colombia tradicionalmente privilegiaba la $\mathrm{OEA}^{7}$. Conformó la Unasur para evitar el aislamiento tras la Operación Fénix ${ }^{8}$. El gobierno Santos trató de utilizar la Unasur para manejar su delicada relación con el gobierno bolivariano, acompañante de sus negociaciones con las FARC. Así, Bogotá aceptó temporalmente que la Unasur compartiera, incluso dominara la resolución de conflictos en América del Sur. Sin embargo, terminó marginándola de la implementación de la paz. Agravada la crisis venezolana, intentó combinar las dos organizaciones en una estrategia transinstitucional, pero luego volvió a privilegiar la OEA, y conformó al Grupo de Lima. Finalmente, el gobierno Duque procedió a salir de la Unasur.

Este artículo consta de tres partes: la primera propone un marco conceptual plural; la segunda examina tres manifestaciones de la competencia AP-Mercosur: la competencia entre el transregionalismo-poligamia y la concentricidad para surtir el modelo preferido de gobernanza económica regional; la utilización colombiana de la AP para contestar el ascenso de Brasil, cuestionando al Mercosur; la inclusión de México en la AP y su extensión fuera del marco suramericano. La tercera aborda la competencia entre la Unasur y la OEA por dominar la gestión de seguridad en América del Sur: a partir de sus acciones superpuestas, analizadas por Nolte (2018), explora las estrategias de Colombia.

Este artículo (observando que las competencias AP-Mercosur y Unasur-OEA dependían de las estrategias de sus miembros) asocia la competencia con las estrategias de balanceo blando (institucional) y de autonomía, y la examina junto con la cooperación (Lee, 2012; 2016). La cooperación se vincula con la aquiescencia o alineamiento, cuando el socio mayor es EE.UU, la potencia hegemónica ${ }^{9}$, pero no se amarra al alineamiento cuando complementa un balanceo blando frente a Brasil (Pastrana, 2016). El conflicto se asocia con el balanceo duro (como sería, por ejemplo, unirse

6 Creado por Colombia y Venezuela con México en 1994, el G3 adoptó regímenes del Tratado de Libre Comercio de América del Norte (TLCAN) en áreas de inversión, servicios, compras públicas, derechos de propiedad intelectual, que la CAN no había regulado, o menos sofisticadamente que el TLCAN. Cuando Venezuela salió de la CAN en 2006, se retiró también del G3.

7 Fundada en 1948, la OEA tenía por objetivo preservar la paz en la región. En los años 50-60 tomó partido en la guerra fría y era un instrumento de la dominación estadounidense. Posteriormente, amplió sus actividades y quedó más independiente de EE. UU. (aunque siguió cargando la herencia de su antigua dominación). Con la Declaración de Santiago de 1991 y la Carta Democrática Interamericana de 2001, asumió un papel más activo en la protección de la democracia (Nolte, 2018, p. 134).

8 Incursión militar colombiana en Ecuador para atacar un campamento de las FARC, que desató una crisis diplomática regional. En el bombardeo pereció el número 2 de las FARC entre unos veinte guerrilleros.

9 Según Russell y Tokatlian (2013), desde finales del siglo XIX, la cuestión de la gran estrategia en América Latina se expresó en dos lógicas que han operado como principios ordenadores de la política exterior de los países de la región: la lógica de la autonomía, dominante, y la lógica de la aquiescencia, secundaria. La excepción ha sido Colombia que adoptó la aquiescencia como gran estrategia dominante, bajo la doctrina respice polum (1914), y solo hizo algunos intentos inconclusos de mayor autonomía y diversificación bajo la doctrina respice similia, desde fines de los 60 
o prestar territorio a una acción militar estadounidense para forzar un cambio de régimen en Venezuela) ${ }^{10}$.

\section{Marco conceptual}

Esta parte presenta un marco conceptual plural - con perspectivas realistas, liberales y constructivistas - para analizar las competencias AP-Mercosur y Unasur-OEA.

\section{El fracaso del ALCA: una divisoria}

La caída del proyecto del Área de Libre Comercio de las Américas (ALCA), confirmado en 2005, abrió paso a una gran diversidad de esquemas en América Latina.

Como el ALCA hubiera reforzado la hegemonía de EE. UU., extendiendo las reglas del Tratado de Libre Comercio de América del Norte (TLCAN) (EE. UU., Canadá, México) al resto del hemisferio, los esquemas latinoamericanos, menos comerciales y más politizados, creados después de su caída, se denominaron regionalismo post-hegemónico (Riggirozzi y Tussie, 2012) o post-liberal (Sanahuja, 2012).

Sin embargo, la corriente proliberal no se extinguió con el ALCA. EE. UU. retomó la vía bilateral, firmando TLC profundos ${ }^{11}$ con socios dispuestos como Chile, Colombia o Perú. Estas economías medianas, para evitar la excesiva dependencia de un solo mercado, adoptarían el transregionalismo, es decir, la estrategia de firmar acuerdos bilaterales con varios socios comerciales en diferentes regiones, elegidos por el tamaño de sus mercados u otras ventajas esperadas (Garzón y Prieto, 2017).

La AP, una zona de libre comercio (ZLC) complementó perfectamente al transregionalismo de sus miembros, pues no les perturbaba en firmar individualmente acuerdos con terceros.

\section{Tipología de los esquemas post-ALCA}

Briceño-Ruiz (2018, 577-586) clasificó las heterogéneas organizaciones regionales, creadas o reformadas tras la caída del ALCA, en tres ejes, apoyados en diferentes modelos de integración económica y de cooperación política.

\section{En integración económica}

10 La asociación bolivariana con Rusia y China puede verse como aquiescencia, así como un balanceo blando frente a EE. UU., tirando en duro si (además de la adquisición de armas) se consideran las recurrentes visitas de bombarderos estratégicos Tu-160 en Venezuela.

11 Tratados de libre comercio que (además de la liberalización comercial) abarcan asuntos relacionados con el comercio: reglas para proteger la propiedad intelectual, las inversiones, el medio ambiente y los derechos de trabajadores que van más allá de lo negociado en el TLCAN o la OMC. 
El Mercosur, que en los años 90 había seguido un regionalismo estratégico ${ }^{12}$ sursur, fue revisado en dimensión social y productiva ${ }^{13}$ por el dúo Lula-Kirchner.

- La Alianza Bolivariana para los Pueblos de Nuestra América (ALBA) aplicó una variedad peculiar del regionalismo social-productivo.

- La AP asumió el regionalismo estratégico, pero como una desviación de su variedad sur-sur que adopta elementos norte-sur de integración profunda.

\section{En cooperación política}

- El Mercosur representaba el modelo autonomista ${ }^{14}$.

- La AP encarnaba el realismo aquiescente ${ }^{15}$.

- El ALBA ensayó el regionalismo contrahegemónico ${ }^{16}$.

\section{El mínimo denominador común - Unasur, CELAC}

La Unasur y la CELAC no tenían dimensión comercial. En cooperación política, ambas se basaban en el mínimo denominador común: el deseo de marginar tanto los objetivos revolucionarios del ALBA, como la idea de la AP sobre la convergencia de intereses con el hegemón global, pero sin adoptar un modelo de autonomía total. De ahí que se paralizaron cuando el consenso era inviable, como en el caso venezolano (Briceño-Ruiz, 2018, pp. 585-586).

12 El regionalismo estratégico liberalizó ampliamente al comercio regional, pero siguió protegiendo sectores vitales para el desarrollo económico. Visto como una expresión del "nuevo regionalismo", prosperó en la ola de integración económica, iniciada a fines de los 80 . A diferencia de los TLC norte-sur, los acuerdos sur-sur (entre países en desarrollo) solían omitir los temas de "integración profunda" (Briceño-Ruiz, 2018, p. 578).

13 El regionalismo social se concibió como un mecanismo para establecer, a nivel regional, normas sociales, políticas redistributivas e instituciones que permitan a los ciudadanos exigir la protección de sus derechos sociales. E regionalismo productivo creó mecanismos para integrar la producción de los miembros de un esquema regional, revitalizando las ideas de la escuela estructuralista (Briceño-Ruiz, 2018, p. 578).

14 En el modelo autonomista, un grupo de países de la periferia utiliza el regionalismo como mecanismo para adoptar políticas comunes en seguridad, derechos humanos y democracia, así como cooperación funcional, sin que estas políticas se subordinen a un hegemón externo. La autonomía impactó los debates sobre la integración regional. Puig (1980) la define como la capacidad máxima de autodecisión que un país podría tener, considerando las condiciones del mundo real (Briceño-Ruiz, 2018, pp. 579-580).

15 El realismo aquiescente se basa en el "realismo periférico" de Escudé (1992). Los países periféricos deben aceptar sus vulnerabilidades y su irrelevancia en la política mundial. Deben revisar sus ideas de autonomía en política exterior, buscar alianzas con grandes potencias y evitar conflictos que luego afectarían sus intereses nacionales. Este modelo propone una convergencia de intereses entre un bloque regional periférico y una o más potencias hegemónicas (Briceño-Ruiz, 2018, p. 579).

16 El regionalismo contrahegemónico podría ser utilizado por un "Estado revolucionario" como un mecanismo para confrontar la hegemonía de una potencia global y regional (Briceño-Ruiz, 2018, p. 579). 


\section{Manifestaciones de la competencia AP-Mercosur}

\section{Transregionalismo versus concentricidad}

La competencia AP-Mercosur se ha librado entre el transregionalismo-poligamia, representado por la AP, y el enfoque concéntrico, representado por el Mercosur, por surtir el modelo privilegiado de gobernanza económica regional.

\section{Transregionalismo}

EE. UU. - cuando volvió a firmar TLC bilaterales con socios proliberales- siguió la estrategia de cabecera y radios. Cuando un radio (como Chile, Colombia o Perú) concluye un TLC bilateral con una cabecera (como EE. UU.), las otras cabeceras (como la Unión Europea o China) también buscan TLC con dicho radio, con miras a obtener para sus empresas competidoras, por lo menos, las mismas concesiones que aquél había otorgado a la primera (EE. UU.). Los radios, por su parte, están presionados a firmar un TLC tras otro con las cabeceras para evitar la desviación de comercio $\mathrm{y}$ de inversiones hacia otros radios que ya tienen tales TLC.

Sin embargo, el transregionalismo permitía a las economías medianas balancear una primera relación comercial asimétrica con un socio grande mediante una segunda, tercera o incluso cuarta relación con socios de talla similar. Así se evitaba que el socio grande se convirtiera en el destino de un porcentaje muy alto de las exportaciones totales del país menor y usara esa dependencia económica como arma política. Además, el país transregionalista podía obtener mayor control sobre el propio proceso de liberalización a través de la selección del país con el cual iniciar negociaciones para un TLC. El tamaño del mercado siguió siendo una consideración dominante, pero con la disponibilidad de múltiples polos cabían otras consideraciones: por ejemplo, elegir países que no constituían una amenaza directa para la industria doméstica o que estuvieran más dispuestos a hacer concesiones en puntos sensibles (Garzón, Prieto, 2017, p. 123).

\section{Concentricidad}

Según Comini y Frenkel (2017), mientras la AP representaba un modelo polígamo, igual al transregionalismo, es decir, una estrategia de múltiples escenarios y velocidades, que priorizaba al mercado internacional a través de negociaciones simultáneas con actores de niveles global, hemisférico y regional, el Mercosur encarnaba un modelo concéntrico.

Tal modelo otorgaba prioridad a los mercados regionales sobre los globales. Sus partidarios partieron de una premisa de asimetría con los actores extrarregionales que limitaba las posibilidades de imponer sus intereses individualmente. Afirmaban la necesidad de definir espacios de consenso no necesariamente comerciales con los vecinos y, una vez establecidos, negociar en bloque con terceros. Buscaban un 
posicionamiento de círculos concéntricos que se expresaba en una estrategia de escenarios escalonados y sucesivos (Comini, Frenkel, 2017, pp. 189-190).

\section{Balanceo blando institucional}

La competencia AP-Mercosur incluyó la contestación institucional, empleada por Colombia y Chile (bajo la primera presidencia de Piñera) frente a la aspiración de Brasil al liderazgo regional.

La contestación institucional es una variedad del balanceo blando ${ }^{17}$, que se ejerce a través de instituciones internacionales.

Según Mijares (2018, p. 264), cuando Brasil se perfilaba como potencia regional, surgieron estrategias de política exterior contradictorias en América del Sur: un (supuesto) balanceo blando colectivo frente a EE. UU., por una parte, y un balanceo blando de potencias secundarias frente a Brasil ${ }^{18}$, por la otra.

Según Flemes y Castro (2016), la AP fue utilizada por Colombia bajo el gobierno de Santos para contestar (balancear) la aspiración brasileña al liderazgo suramericano, cuestionando al Mercosur e impugnando sus reglas.

Los autores definieron la contestación institucional como una estrategia de las potencias secundarias de una región para cuestionar la legitimidad, la centralidad o la eficacia de las instituciones lideradas por las potencias primarias $\mathrm{y}$, posiblemente, las normas y los valores que sirven de base al orden regional existente (Flemes, Castro, 2016, p. 84).

Así, la contestación institucional es revisionista en sus fines, pero indirecta en sus medios (Ebert, Flemes, Strüver, 2012; Flemes, Castro, 2016).

Lee $(2012 ; 2016)$ captó los comportamientos cooperativos junto a los competitivos en la dinámica del balanceo institucional. Con fines analíticos, distinguió entre balanceo interinstitucional e intrainstitucional, dos estrategias aplicadas a menudo de forma combinada por Estados individuales.

En el balanceo intrainstitucional, los Estados cooperan para crear una institución, cuando la demanda de bienes colectivos es alta. Sin embargo, una vez creada la institución para proveer el bien colectivo, revelan en su marco comportamientos tanto cooperativos, como balanceadores para ganar influencia. La cooperación y los conflictos coexisten dentro de la institución (Lee, 2016).

17 Las potencias intermedias -en vez de recurrir al costoso y arriesgado balanceo duro de poder, movilizando recursos bélicos propios o conformando alianzas militares- pueden optar por el balanceo blando, utilizando instituciones internacionales, medios económicos de influencia (economic statecraft), quizás una limitada acumulación de armas y ocasionales ejercicios militares. Sin embargo, el balanceo blando también busca un efecto, por lo menos, indirecto en las perspectivas militares de un Estado superior (Pape, 2005; Merke, 2015).

Tales balanceos de potencias secundarias frente a Brasil se analizan por Flemes y Wehner (2015). 
En el balanceo interinstitucional, un Estado crea instituciones separadas o superpuestas para balancear la influencia de un Estado-objetivo, con miras a reconfigurar la arquitectura institucional de la región a expensas de este último. Los Estados balanceadores compiten por atraer otros Estados a su institución, mientras evitan incorporarse a las instituciones dominadas por el Estado objetivo (Lee, 2016).

\section{Complejo suramericano de gobernanza - trascendido por la AP}

Nolte (2014) evaluó el complejo suramericano de gobernanza ${ }^{19}$ como cooperativo $^{20}$. Entre las organizaciones de enfoque exclusivamente suramericano (Unasur, CAN, Mercosur) no observó ninguna constelación de conflicto.

Sin embargo, en parte, para contrapesar al Mercosur, la AP incorporó a México, rival de Brasil en América del Sur. De esta manera, según Mijares y Nolte (2018), se originó una fractura geopolítica regional, que resultó en una relatinoamericanización del complejo suramericano, resaltando las contradicciones y los desencuentros.

\section{Manifestaciones de la competencia Unasur-OEA}

\section{Superposiciones de miembros, mandatos y acciones}

La Unasur estaba anidada en la OEA, es decir, la OEA incluía a todos los miembros de la Unasur y las dos organizaciones también se traslapaban en su principal mandato: la protección de la democracia y la mediación en conflictos (Nolte, 2018). Así, competían para ejercer dicho mandato en América del Sur.

\section{Superposiciones entre los mandatos de la Unasur y la OEA}

Weiffen, Wehner y Nolte (2013), tras analizar las superposiciones entre los mandatos de la Unasur y la OEA, llegaron a las siguientes conclusiones: La Unasur, en su desarrollo, replicó varias concepciones y prácticas de la OEA en materia de seguridad $^{21}$. La creación de la Unasur fue impulsada por consideraciones relacionales, a saber: la exclusión de EE. UU. de América del Sur; la intención de Brasil y, en menor medida, de Venezuela a utilizar la organización como vehículo para consolidar su influencia en la región.

La diferenciación entre América del Sur y el resto del continente solo apareció como la razón de ser de la Unasur, cuando se le analizaba junto con las motivaciones

19 Un complejo de gobernanza regional es la más amplia configuración de organizaciones regionales que enmarcan el discurso regional de los Estados miembros y generan las reglas para la región en diversas áreas de política, contribuyendo a resolver problemas y aportar bienes colectivos (Nolte, 2014).

20 Un complejo cooperativo tiene una organización central "politemática" y conectada con las demás organizaciones regionales. Las principales normas que esta apoya no se discuten. Todos los grandes actores colaboran con ella y con el proyecto regional relacionado con ella, aunque no todos apoyen las mismas organizaciones.

21 En este proceso, los miembros de la Unasur han actuado como transmisores: aprovechando su doble membresía y su conocimiento del desarrollo institucional relevante de la OEA, han adoptado, reinterpretado y modificado normas e instituciones de la OEA (Weiffen, Wehner, Nolte, 2013, p. 384). 
de poder de grandes Estados suramericanos: sus aspiraciones a crear una alternativa a la OEA y excluir la OEA y a EE. UU. de los asuntos subregionales, se manifestaban en los conceptos y las prácticas de seguridad que la Unasur venía desarrollando (Weiffen, Wehner, Nolte 2013, 384).

\section{Superposición de acciones Unasur-OEA}

Nolte (2018) reconstruyó nueve episodios donde las superposiciones de jure entre la Unasur y la OEA resultaron en superposiciones de acciones. De los contradictorios argumentos teóricos, relativos a los riesgos y los beneficios de la superposición ${ }^{22}$, dedujo hipótesis alternativas y las verificó en dichos episodios concretos.

Sus pares de hipótesis indagaron qué efectos tenían las acciones superpuestas de la Unasur y de la OEA para la cooperación regional: Si la redundancia de sus recursos humanos e institucionales facilitaba los acuerdos creando un baipás en caso de bloqueos o pasaba lo contrario. Si su competencia llevaba a la adopción de mejores normas o las diluía e incluso las subvertía. Si el forum shopping, es decir, la elección del escenario (organización) considerado como más favorable, por parte de ciertos miembros paralelos facilitaba los acuerdos multilaterales o los obstaculizaba (Nolte, 2018, p. 133).

Los nueve episodios eran: 1. La crisis en Bolivia, 2008; 2. El conflicto relativo a las bases militares de EE. UU. en Colombia, 2009; 3. La crisis colombo-venezolana, 2010; 4. La crisis ecuatoriana, 2010; 5. La crisis paraguaya, 2012; 6. Venezuela 1, 2013-2015; 7. Venezuela-Colombia, 2015; 8. Venezuela 2, 2015; 9. Venezuela 3, 2016-2017.

El resultado era mixto, la superposición de acciones entre la Unasur y la OEA unas veces beneficiaba la cooperación regional y otras veces la perjudicaba.

Según la evaluación de Nolte (2018, p. 148), en cinco episodios, la redundancia OEA-Unasur que permitía estrategias transinstitucionales ayudó a superar un bloqueo en una de las dos organizaciones, aunque en un episodio generó bloqueo. En cuatro casos de competencia las normas internacionales mejoraron y se afianzaron, pero en otros cuatro sufrieron dilución y hasta subversión, cuando Venezuela era un actor clave. El forum shopping tuvo un efecto negativo en dos casos y positivo en cuatro.

Cuando la superposición benefició la cooperación regional, la competencia de las dos organizaciones resultó en una cooperación involuntaria.

22 En un extremo, la superposición podría conducir a la fragmentación del derecho internacional, así como a bloqueos y parálisis entre organizaciones regionales. En el otro extremo, la diversidad y la superposición de organizaciones regionales podrían reducir el riesgo de que la integración y cooperación regional se estancara. La superposición introduce flexibilidad institucional y trae una nueva dinámica a las relaciones intrarregionales (Nolte, 2018, p. 133). 
En todo caso, Nolte $(2018$, p. 148) concluyó que las organizaciones regionales anidadas conllevaban un potencial específico de conflicto, el choque sobre los ámbitos regionales o más precisamente sobre el derecho exclusivo de ejercer un mandato determinado dentro de un ámbito regional.

\section{Búsqueda de autonomía suramericana}

La competencia Unasur-OEA emanaba de una búsqueda de autonomía suramericana, apoyada en el ascenso de Brasil.

\section{El Consejo de Defensa Suramericano}

A instancias de Brasil, los miembros de la Unasur crearon el Consejo de Defensa Suramericano (CDS) como una plataforma potencial para resolver conflictos y fomentar la cooperación militar regional. El CDS, según su Estatuto (2008), se creó como una instancia de consulta, cooperación y coordinación en materia de defensa, con miras a consolidar América del Sur como una zona de paz, construir una identidad suramericana en defensa, adoptar medidas de fomento de la confianza, promover la cooperación en la industria de defensa, y fomentar el intercambio en la formación militar.

\section{Seguridad cooperativa - no colectiva}

En las conversaciones previas a la creación del CDS, el bloque liderado por Venezuela pidió una alianza militar completa, pero la idea de una "Organización del Tratado del Atlántico Sur” fue descartada (Comini, 2010).

El grupo liderado por Brasil y Argentina buscó un mecanismo de disuasión colectiva para la zona. El ministro de defensa brasileño Jobim argumentó que el instrumento de defensa de la Unasur debía tener, por lo menos, características disuasorias, ante todo debía excluir a EE. UU. explícitamente (Mijares, 2018).

Colombia, que estrechó sus lazos militares con EE. UU., evitó cualquier compromiso relativo a un acuerdo regional de seguridad; Chile abogó con éxito por un diseño institucional de compromisos mínimos. Como resultado de estas contradicciones, América del Sur alcanzó un acuerdo de seguridad orientado a la autonomía regional y las medidas de confianza mutua (Mijares, 2018, p. 263).

\section{Proyecto de comunidad de seguridad}

El CDS iba a ser el germen de una Comunidad suramericana de seguridad ${ }^{23}$. Según Lepage (2011), sus programas conjuntos apuntaban hacia:

23 Comunidades de seguridad: Deutsch et al. (1957) consideraban la integración como una asociación voluntaria para evitar cualquier enfrentamiento armado: un proceso de aprendizaje durante un prolongado período de extenso contacto entre grupos de personas de los estratos políticamente relevantes. Surge una conciencia de comunidad: una "percepción de nosotros" y una convicción ampliamente compartida de que los problemas comunes pueden ser resueltos en común de manera pacífica. 
- El segundo nivel de la estructura de Adler, Barnett (1998) elaborado para el estudio de las comunidades pluralistas de seguridad (CPS), donde (en la categoría de procesos) las organizaciones internacionales contribuyen a la confianza mutua y la identidad colectiva, definiendo normas y estableciendo mecanismos y sanciones para fortalecerlas.

- La segunda fase (ascendente) del desarrollo de las CPS, con esfuerzos para crear una identidad compartida mediante prácticas y hábitos (incluyendo la diferenciación entre "nosotros y ellos"). Sin embargo, Flemes, Nolte y Wehner (2011) previeron que los divergentes intereses materiales e ideológicos impedirían la profundización de esta cooperación.

\section{La paradoja de las autonomías}

Según Mijares (2018), la razón por la cual el CDS nunca logró una operatividad acorde con su diseño institucional, era que su proyecto de autonomía en seguridad regional fue socavado por las aspiraciones de autonomía nacional.

Los miembros del CDS debieron abandonar las posturas maximalistas (Venezuela, Ecuador) y minimalistas (Colombia, Chile) para lograr el consenso y así garantizar un nivel mínimo de cohesión, en busca de tanta autonomía nacional como era posible y tanta autonomía regional como era necesario (Mijares, 2018, p. 276).

Para una potencia regional como Brasil, la creación de un esquema suramericano de seguridad hubiera servido de plataforma para proyectarse como emergente potencia global, de manera que aquí no habría diferencia entre autonomía nacional y regional. Sin embargo, los ejecutivos de política exterior de las potencias secundarias como Argentina, Chile, Colombia, Perú, Venezuela, e incluso de menores estados como Ecuador, jalaban en diferentes direcciones, influidos por asociaciones externas, rivalidades ideológicas y conflictos fronterizos (Mijares, 2018, p. 277).

\section{EI conflictivo complejo hemisférico de gobernanza}

Nolte (2014) evaluó al complejo hemisférico como conflictivo, si bien con elementos de cooperación y segmentación ${ }^{24}$. En particular, detectó una constelación de conflicto entre la Unasur y la OEA. Si bien su marco analítico no tenía término medio entre cooperación y conflicto, cabía esperar una intensa competencia Unasur-OEA, más cercana al conflicto que a la cooperación.

24 En un complejo conflictivo, la organización central y las otras organizaciones están en competencia por miembros y mandatos. Ciertas normas básicas están en conflicto. Los grandes actores apoyan distintas organizaciones y promueven distintos proyectos regionales (Nolte, 2014, p. 11). 


\section{La competencia AP-Mercosur - modelo de gobernanza económica regional}

La AP y el Mercosur compitieron ofreciendo modelos diferentes para la gobernanza económica regional, a saber: el transregionalista-polígamo y el concéntrico, respectivamente. Además, la AP fue utilizada por Colombia para contestar el ascenso de Brasil. A iniciativa colombo-chilena, México se incorporó en la AP, en parte, para contrapesar al Mercosur. Así, la AP se extendió fuera del cooperativo complejo suramericano de gobernanza.

\section{Competencia entre estrategias comerciales}

El avance del modelo transregionalista-polígamo, representado por la AP, se manifestó en la multiplicación de acuerdos de complementación económica (ACE) entre miembros de la AP y del Mercosur, seguida por un cambio en las estrategias de Argentina y hasta Brasil.

Los ACE cruzados entre miembros de la AP y del Mercosur - en el marco de la Asociación Latinoamericana de Integración (ALADI) - comenzaron a multiplicarse ya en los años anteriores del impeachment de Rousseff en Brasil. Estos ACE bilaterales complementaban paquetes preexistentes, como los acuerdos de libre comercio de bienes entre los miembros del Mercosur y sus asociados andinos, algunos llegando hasta TLC completos.

Tras la reorientación proliberal de Argentina y Brasil desde 2015/16, la estrategia polígama de Chile, Colombia y Perú iba prevaleciendo en la Unasur, relevando la cohesión inicial en torno al modelo concéntrico. En consecuencia, América del Sur dejaba de ser una entidad estratégica (Comini, Frenkel, 2017, p. 190).

El Mercosur limitó sus negociaciones en bloque a los grandes socios extrarregionales, reanudando la maratón con la Unión Europea (UE) sobre un elusivo TLC interregiona ${ }^{25}$. Sin embargo, los miembros pequeños del Mercosur siguieron buscando TLC bilaterales con otros grandes terceros (EE. UU., China) revelando la debilidad del esquema austral.

El Mercosur no tenía un mercado regional homogéneo, ni una real unión aduanera (UA), ni siquiera libre comercio automotriz, y tampoco era activo en negociar nuevos acuerdos. El fondo estructural, que beneficiaba a Paraguay y Uruguay, era ínfimo. Así las cosas, los intereses divergentes de los miembros grandes y los pequeños ante un TLC con China se manifestaron más agudamente (Briceño-Ruiz, 2018a, p. 216) ${ }^{26}$.

25 Según Gratius (2017, p. 12), el “interregionalismo asimétrico" falló, porque en los ámbitos de interés para la UE (servicios, industria automotriz), el Mercosur no actúa como entidad colectiva, sino se divide en cuatro políticas nacionales. Pero la UE tampoco puede actuar como un solo actor. La credibilidad de la Comisión como negociadora exclusiva es socavada por el proceso decisorio multinivel y por la fuerte influencia de los lobbies agrícolas de Francia, Polonia y de otros Estados miembros, cuyos intereses están representados por un proteccionista comisario de agricultura y el Parlamento Europeo.

26 Uruguay y Paraguay tenían incentivos para negociar una apertura con China, pero Brasil y Argentina tendrían altos costos en los sectores textil y automotriz. 


\section{El uso colombiano de la AP para contestación institucional}

Según Flemes y Castro (2016), el gobierno Santos utilizó la AP para contestar la aspiración brasileña al liderazgo en América del Sur, cuestionando al Mercosur e impugnando sus reglas.

La AP representaba una alianza diplomática entre tres potencias secundarias de América del Sur. Además, incorporó a México, excluido de la delimitación geopolítica brasileña de la región. Tal alianza buscaba fortalecer la cooperación económica entre Estados afines, con miras a ejercer mayor influencia sobre la potencia regional (Flemes, Castro, 2016, p. 84).

Esta estrategia podía interpretarse como buffering -es decir, la estrategia de una potencia secundaria que profundiza su cooperación económica y securitaria con otros Estados para acrecentar su influencia sobre la potencia primaria- en cuatro sentidos (Flemes, Castro, 2016, pp. 80-84):

1. Contestación institucional: la AP representaba la continuación del regionalismo abierto (transformado en transregionalismo) que contrastaba con el regionalismo postliberal, apoyado por Brasil.

2. Balanceo interinstitucional: la AP cuestionaba la relevancia del Mercosur, promovido por Brasil. La AP se lanzó en 2011 con un intenso marketing presidencial, como una alternativa al Mercosur.

3. Balanceo institucional excluyente: la AP excluyó a Brasil.

4. Deslegitimación: la AP servía como una plataforma para deslegitimar las instituciones lideradas por Brasil, impugnando sus normas regionales, especialmente las del Mercosur (Flemes, Castro, 2016, p. 84).

En el marketing mediático, la AP fue identificada con un Modelo Pacífico (liberal, dinámico, innovador) y el Mercosur con un Modelo Atlántico (proteccionista, politizado, estancado) (Tvevad, 2014) ${ }^{27}$.

Cabe recordar que tal contestación colombiana a Brasil era solo institucional, y se complementaba con diversos comportamientos cooperativos: acuerdos bilaterales de todo tipo; ACE cruzados entre miembros de la AP y del Mercosur; activismo inicial en la Unasur y un intento de mediar en Venezuela con los cancilleres de Brasil y Ecuador; y asistencia a las conversaciones AP-Mercosur.

Colombia bajo Santos abandonó el balanceo duro colateral de Uribe, y pasó a una estrategia revisionista indirecta (Flemes y Castro, 2016). Como resumió Pastrana (2016), el gobierno Santos empleaba un complejo balanceo blando frente a Brasil,

27 Según Mijares (2018), la división de América del Sur en dos ámbitos subregionales, Atlántico y Pacífico, se originó en la salida de Venezuela de la CAN y su interés en unirse al Mercosur. 
comprendido entre dos principios básicos: cooperación sin alineamiento y contestación sin balanceo duro.

\section{La AP trasciende al complejo suramericano de gobernanza}

La AP se extendió fuera del complejo suramericano de gobernanza, calificado por Nolte (2014) como cooperativo. La AP excluyó a Brasil e incluyó a México, conduciendo a una tensa relatinoamericanización del marco suramericano (Mijares y Nolte, 2018).

Además, la AP trascendió la región debido al transregionalismo de sus miembros, tres de los cuales forman parte del Tratado Integral y Progresista de Asociación Transpacífico (CPTPP), y debido a su propia proyección hacia Asia-Pacífico mediante las asociaciones negociadas con Canadá, Singapur, Australia y Nueva Zelanda, respectivamente. Esas negociaciones $4+1$, curiosamente, eran cercanas a un interregionalismo flexible.

\section{La competencia Unasur-OEA - mandato de la seguridad regional}

La Unasur y la OEA competían por el mandato de la gestión de seguridad en América del Sur, mientras los Estados de la región mantenían activa su doble membresía.

\section{Competencia Unasur-OEA - estrategias colombianas}

De los episodios, utilizados por Nolte (2018) para verificar los efectos de la superposición de acciones Unasur-OEA sobre la cooperación regional, se resumen aquí tres que revelan las estrategias colombianas.

- La redundancia crea un baipás: En 2009, con la OEA inactiva, el acuerdo sobre el uso extendido de bases colombianas por EE. UU. se discutió en la Unasur, con la participación del presidente Uribe. Como resultado, se establecieron parámetros normativos iniciales para la presencia de las fuerzas militares extranjeras en América del Sur (Nolte, 2018, p. 137).

- Forum shopping: En 2010, por iniciativa del gobierno Uribe, la OEA convocó una sesión para discutir el refugio de líderes de las FARC en Venezuela. El presidente Chávez negó la jurisdicción de la OEA, cortó relaciones con Colombia, y solicitó una reunión de la Unasur. El presidente Santos, apenas posesionado, se reunió con su homólogo venezolano, bajo la mediación del secretario general de la Unasur Kirchner, para normalizar las relaciones bilaterales. El forum shopping negativo de Chávez y positivo de Santos permitió un acuerdo (Nolte, 2018, pp. 137-138).

- Estrategia transinstitucional (fallida): En 2015, cuando Venezuela cerró las fronteras, causando problemas humanitarios, Colombia propuso discutir el tema tanto en la OEA, como en la Unasur. El gobierno Maduro aceptó la Unasur, pero rechazó la OEA. Cuando la solicitud colombiana en la OEA 
quedó bloqueada, Caracas dejó de tener prisa para proceder en la Unasur. Bogotá retiró su propuesta para no arriesgar otro revés en un foro internacional (Nolte, 2018, p. 143).

\section{La Unasur logra elecciones transparentes en Venezuela}

Otro episodio importante se refirió a las elecciones legislativas de 2015 en Venezuela. La Unasur fue autorizada a acompañar las elecciones, mientras la oferta de monitoreo de la OEA fue rechazada. Gracias a la gestión de la Unasur y de su secretario general Samper, estas elecciones resultaron transparentes y, por ende, ganadas ampliamente por la oposición.

Si bien la misión in situ era de la Unasur, Nolte (2018, p. 144) otorgó parte del crédito a las advertencias epistolares del secretario general de la OEA Almagro. Tal presión "redoblada" puede verse como una cooperación involuntaria entre las dos organizaciones competidoras.

Para el presidente Maduro, la evidente lección de la derrota electoral debió ser que sin manipular el sistema político no podría mantenerse en el poder. Así, se hizo estéril toda mediación sucesiva, pues el Gobierno bolivariano no haría ninguna concesión real a la oposición.

\section{La Unasur es marginada de la paz colombiana}

La Unasur se debilitó sensiblemente, cuando quedó marginada del proceso de paz en Colombia, donde esperaba tener una contribución significativa. Esta historia la formulamos aquí como un episodio adicional de competencia indirecta Unasur-OEA:

En las negociaciones de paz, las decisiones se tomaban de común acuerdo entre el gobierno Santos y las FARC. Los guerrilleros rechazaron la OEA por haber prestado asistencia técnica a la desmovilización de sus enemigos paramilitares. En cambio, favorecían la inclusión de la Unasur en la verificación, a pesar de su escasa experiencia en este campo (Betancourt, 2016).

En abril de 2015, Samper propuso que la fuerza de paz argentino-chilena Cruz del Sur fuera la encargada de verificar el desarme guerrillero (Samper, 2015). En julio, la presidencia uruguaya de la Unasur delegó a un exministro uruguayo de defensa para participar, junto con un delegado del secretario general de la ONU, en la verificación del desescalamiento previo al cese al fuego. Santos aseguró a la opinión colombiana que Bayardi no representaba a la Unasur sino a Uruguay (Santos, 2015).

A principios de 2016, el presidente colombiano anunció que los observadores, que designaría la ONU para verificar el cese al fuego definitivo y el desarme guerrillero, serían nacionales de los países miembros de la CELAC, pero no podrían ser de ningún país limítrofe de Colombia, sin mencionar la Unasur (Santos, 2016). 
Aunque la ONU se encargara de verificar el desarme guerrillero y la implementación de los acuerdos, la OEA logró conservar su Misión de Apoyo al Proceso de Paz (MAPP). ${ }^{28}$ Así, la OEA ganó la competencia indirecta con la Unasur que no pudo entrar en ese "mercado" debido a la resistencia mayoritaria de la élite política y militar colombiana.

Mijares $(2018,273)$ constató que para el CDS-Unasur no había un papel designado en el proceso colombiano de paz. El CDS, a su vez, no identificó la crisis venezolana como una amenaza a la seguridad regional.

\section{Autonomía regional - aversión colombiana}

Si bien el gobierno Santos, en aras de manejar su delicada relación con el gobierno bolivariano, acompañante de sus negociaciones de paz con la FARC, aceptó temporalmente que la Unasur compartiera la gestión de conflictos en América del Sur, no favorecía realmente una autonomía regional, ni mucho menos un balanceo blando colectivo frente a EE. UU.

Lo que buscaba Colombia era una asociación bilateral menos asimétrica con EE. UU., asumiendo mayor papel en su red global, ya sea mediante la exportación triangulada de experticia militar colombiana a México y Centroamérica, con cofinanciación estadounidense (Tickner, 2016), o mediante la asociación con la OTAN.

En América del Sur, la política colombiana de cooperación en seguridad siguió siendo bilateral y minimalista, centrada en sus fronteras con Brasil, Perú y Ecuador. Colombia era renuente a cooperar con las fuerzas armadas venezolanas en el marco del CDS, y no estaba interesada en la centralización de la toma de decisiones (Mijares, 2018, pp. 266, 273).

Colombia tampoco alcanzó una cooperación significativa con Brasil en esta área. Radseck (2017) resumió las limitantes colombianas:

- La falta de una diferenciación entre seguridad interior y defensa nacional; la aversión a transparentar datos del sector defensa; la persistencia de la Doctrina de Seguridad Nacional, ajena a las posiciones conceptuales, institucionales y operativas de Brasil, Argentina, Chile y Uruguay (Radseck, 2017, pp. 82-83).

- El estrecho alineamiento con la agenda antidroga de Washington. Aunque la conflictiva estrategia de intervención por invitación (Tickner, 2007) se reemplazara por estrategia triangular, no ocurrió un cambio de paradigma, sino se reafirmó el compromiso constante de los gobiernos colombianos a cultivar la más íntima cooperación con el Pentágono. Esta configuración mental de la clase política colombiana llegó a formar parte de la razón de Estado (Radseck, 2017, pp. 83-84).

28 Después de monitorear la desmovilización paramilitar en 2004, la MAPP-OEA enfocaba su apoyo a las comunidades y las víctimas. Hoy hace énfasis en la sustitución de cultivos ilícitos y la protección de líderes sociales y campesinos amenazados por diferentes actores armados. 
Según Mijares (2018, p. 272), Brasil y Colombia alcanzaron una primera aproximación en términos de seguridad multidimensional en 2012, logrando acuerdos de cooperación en 2016 (ya bajo Temer como presidente interino). En 2017, Brasil lideró ejercicios conjuntos en la triple frontera con fuerzas armadas de Colombia, Perú y EE. UU., fuera del marco CDS.

\section{El Grupo de Lima - desarticulación del complejo suramericano}

Cuando Argentina y Brasil pasaron del campo autonomista al aquiescente, uniéndose a los miembros de la AP para aislar la autocracia bolivariana, se aceleró la desarticulación del complejo suramericano de gobernanza.

Los fundadores del Mercosur suspendieron a Venezuela como Estado Parte a fines de 2016, por no haber internalizado la normativa comunitaria y, en agosto de 2017, por vulnerar el orden constitucional, aplicándole la cláusula democrática del esquema austral.

La Unasur cedió la iniciativa a la OEA que había intentado desplazar. Sin embargo, los miembros del ALBA conservaban, junto con los de Petrocaribe, una minoría de bloqueo en la OEA, suficiente para impedir la suspensión de Venezuela por alteración/ruptura del orden constitucional-democrático, aunque no para evitar la activación del proceso de aplicación de la Carta Democrática Interamericana (CDI).

Tal estancamiento motivó la formación del Grupo de Lima, una coalición informal para manejar una vecindad "incongruente" entre gobiernos proliberales, volcados hacia EE. UU., y el gobierno bolivariano, antiliberal, asociado con China y Rusia (Kourliandsky, 2019).

Concretamente, el Grupo, integrado por los principales Estados latinoamericanos y Canadá, condenó las sentencias por las cuales el Tribunal Superior de Justicia (TSJ), inflado con jueces chavistas, se arrogó las competencias legislativas de la Asamblea Nacional legítima, dominada por la oposición; la elección inconstitucional de una Asamblea Nacional Constituyente como alternativa; la represión de manifestaciones de protesta; el proceso electoral manipulado, que resultó en la reelección de Maduro, en un sufragio boicoteado por la mayoría de la oposición.

La Unasur quedó amenazada de extinción en 2018, cuando sus principales miembros, pertenecientes al Grupo de Lima, suspendieron su participación y sus pagos al presupuesto. Los pesos pesados querían reorientar la Unasur a la infraestructura regional, pero Caracas se aferraba a la regla de consenso. El Electo presidente de Colombia, Duque, visitó la OEA para anunciar el retiro de la Unasur. Después de su toma de posesión, Bogotá notificó a la Unasur de su salida. Duque (2018) adujo dos razones: la Unasur fue creada para fracturar al Sistema Interamericano, y se hizo "cómplice de la dictadura" venezolana. 


\section{Conclusiones}

El dúo AP-transregionalismo parecía prevalecer en la competencia con el modelo concéntrico del Mercosur, incapaz de completar su UA, ni su ZLC interna.

En años recientes, los miembros del Mercosur y de la AP multiplicaron sus ACE cruzados en marco ALADI. Hasta México y Brasil, cuya rivalidad geopolítica impidió una amplia apertura recíproca de mercados, prometieron profundizar su ACE 53 (Briceño-Ruiz, 2018a, p. 221).

El Mercosur redujo las negociaciones en bloque a sus socios extrarregionales, reanudando la maratón con la UE sobre una asociación birregional, pero sus miembros pequeños siguieron buscando TLC bilaterales con otros grandes terceros.

El transregionalismo concordaba con la estructura comercial de América Latina, donde no hay una cabecera regional comparable a China en Asia. EE. UU. es una cabecera más importante que las mayores naciones latinoamericanas. El comercio se concentra fuera de la región, con EE. UU., China y la UE como los mayores mercados (Nolte, 2017).

Sin embargo, las estrategias transregionalistas requerirían un régimen abierto de comercio internacional, que ha sido socavado cada vez más por el proteccionismo, latente desde la crisis económica de 2008 y patente desde la investidura de Trump en $2017^{29}$.

La competencia AP-Mercosur no pasaba del balanceo blando, y si la AP trascendió la región en varios sentidos, también venía conversando de convergencia con el Mercosur, formalmente desde 2016.

Además, la competencia AP-Mercosur se atenuó con la desaparición de la dicotomía Pacífico/Atlántico tras el giro proliberal de Argentina y Brasil (Briceño-Ruiz, 2018a).

Por otra parte, Garzón y Prieto (2017) minimizaron dicha competencia, argumentando que ni la AP era la principal estrategia comercial de sus miembros, ni el Mercosur la era para Brasil, que aplicaba una estrategia de tamaño de (su propio) mercado. Sin embargo, el Mercosur ha sido crucial para Brasil políticamente, como el núcleo de su cooperación con Argentina, su socio estratégico más importante ${ }^{30}$.

Finalmente, tanto los miembros de la AP como los del Mercosur forman parte de la Aladi. Los suramericanos de la AP son asociados del Mercosur. Los miembros

29 EE. UU. abandonó el Tratado de la Asociación Transpacífico (TPP); renegoció el TLCAN a costa de México (como plataforma manufacturera) y de los terceros; arriesgaba una mayor guerra comercial con China y disuadía a sus socios de concertar acuerdos con ella; clavaba sanciones a Rusia y Venezuela.

30 Durante 20 años de infructuosas negociaciones Mercosur-UE, Brasil ni siquiera exploró un acuerdo bilateral con Bruselas, para no arriesgar un conflicto con Argentina (Gratius, 2017). Como recordó Valladão (2014), la creación del Mercosur en 1991 transformó el ciclo histórico de rivalidad latente entre Buenos Aires y Brasilia en una relación de cooperación sostenible. 
fundadores del Mercosur, excepto Brasil, son observadores de la AP. Tales superposiciones pueden servir de puentes entre los dos esquemas, aunque también pueden diluir su cohesión interna (Tvevad, 2014).

En tiempos de crisis, el Banco Mundial (2017) sugirió aprovechar pragmáticamente el potencial de liberalización ya acumulado en América Latina y el Caribe, y abogó por una gran ZLC regional (basada en un TLC AP-Mercosur) que, además de la desgravación arancelaria, armonizaría normas sanitarias y fitosanitarias, y desmontaría obstáculos técnicos al comercio (Nolte, 2018a, p. 19).

La Unasur estaba anidada en la OEA, lo cual agudizó su competencia por el mandato de la gestión de seguridad en América del Sur. La evaluación del complejo hemisférico de gobernanza como conflictivo ayudó a explicar esa intensidad.

La competencia Unasur-OEA a veces resultó en cooperación involuntaria, como en el caso de las presiones paralelas para la transparencia de las elecciones legislativas venezolanas de 2015. La contundente derrota electoral debió convencer al presidente Maduro de que sin manipular el sistema político venezolano no podría mantenerse en el poder. De ahí la esterilidad de las mediaciones posteriores.

La Unasur se debilitó cuando quedó marginada de la verificación de la paz en Colombia, perdiendo la competencia indirecta con la OEA que logró conservar su MAPP.

La desarticulación del cooperativo complejo suramericano de gobernanza, apoyado en la Unasur como organización central, se aceleró cuando Argentina y Brasil pasaron del campo autonomista al aquiescente, aislando la autocracia venezolana que persistía en su ideario revolucionario.

Ineficaz mediadora en la crisis venezolana, la Unasur cedió la iniciativa a la OEA, pero los miembros del ALBA, junto con los de Petrocaribe, conservaban en su seno una minoría de bloqueo, suficiente para impedir la suspensión de Venezuela.

Tal impase motivó la creación del Grupo de Lima, una coalición para manejar la vecindad incongruente entre los grandes latinoamericanos proliberales, volcados hacia EE. UU., y una Venezuela autodefinida como socialista del siglo XXI, asociada con China y Rusia.

La Unasur quedó amenazada de extinción cuando sus mayores miembros, pertenecientes al Grupo, suspendieron su participación en ella. El bajo costo de salida de la Unasur demostró que un proyecto de integración regional debía incluir una significativa dimensión comercial (Nolte, 2018a).

Comparando las dos competencias, mientras la AP parecía prevalecer en la competencia de modelos de gobernanza económica con el Mercosur, la Unasur no solo perdió la competencia con la OEA por el mandato de seguridad en América del Sur, sino quedó amenazada de extinción. 
La competencia Unasur-OEA era mucho más propensa a derivar en conflicto, que la competencia AP-Mercosur. La cooperación involuntaria Unasur-OEA no atenuaba su competencia, y distaba mucho de los conscientes esfuerzos de convergencia AP-Mercosur.

Mientras la competencia Unasur-OEA emanaba de un intento de autonomía suramericana, apoyada en el ascenso de Brasil, la contestación colombiana vía AP a su aspiración de liderazgo regional era parte de la competencia AP-Mercosur.

El gobierno Santos aceptó temporalmente que la Unasur compartiera la gestión de conflictos en América del Sur, en aras de manejar su relación con Venezuela en el proceso de paz, pero no favoreció el CDS y su cooperación de seguridad siguió siendo bilateral y minimalista, centrada en las fronteras con Brasil, Perú y Ecuador.

Cualquier cooperación colombiana en la Unasur se compensaba por la asociación con la OTAN o la exportación triangulada de experticia militar. Sin embargo, la búsqueda colombiana de una asociación bilateral menos asimétrica con EE. UU. cabía en una aquiescencia, interpretada ampliamente.

\section{Referencias}

Adler, E., Barnett, M. (1998). Security Communities. Cambridge University Press.

Banco Mundial. (2017). Better Neighbors: Toward a Renewal of Economic Integration in Latin America. Washington D.C.: World Bank.

Betancourt, R. (2016, enero). Los organismos hemisféricos y regionales en el posconflicto colombiano. En Pastrana, Eduardo, Gehring, Hubert. (Eds.). Política exterior colombiana: escenarios y desafios en el posconflicto, 318-345.

Briceño-Ruiz, J. (2018). Times of Change in Latin American Regionalism. Contexto Internacional, 40(3). Recuperado de http://dx.doi.org/10.1590/S01028529.2018400300008

Briceño-Ruiz, J. (2018a). ¿Regionalismo, interregionalismo o bilateralismo?: Los retos de América Latina frente a la turbulencia global. En Tremolada, E. (Ed.). La cooperación internacional como alternativa a los unilateralismos. Bogotá: Universidad Externado de Colombia.

Comini, N. (2010, noviembre-diciembre). El rol del Consejo de Defensa de la Unasur en los últimos conflictos regionales. Nueva Sociedad, No. 230, 14-22.

Comini, N., Frenkel, A. (2017). Unasur. De proyecto refundacional al fantasma del Sudamexit. CRIES. Anuario de Integración Regional de América Latina y el Caribe, 13, 181-207. 
Deutsch, K. et al.(1957). Political Community in the North-Atlantic Area: International Organization in the Light of Historical Experience. Princeton University Press.

Ebert, H., Flemes, D., Strüver, G. (2012). The Politics of Contestation in Asia: How Japan and Pakistan Deal with their Rising Neighbors. GIGA. Working Paper 206. Hamburg.

Flemes, D., Castro, R. (2016). Institutional Contestation: Colombia in the Pacific Alliance. Bulletin of Latin American Research, 35(1), 78-92.

Flemes, D., Nolte, D., Wehner, L. (2011). Una comunidad de seguridad regional en formación: la Unasur y su Consejo de Defensa. Estudios Internacionales 170, 105-127. Universidad de Chile.

Flemes, D., Wehner, L. (2015). Drivers of strategic contestation: The case of South America. International Politics, 52(2), 163-177.

Escudé, C. (1992). El realismo periférico. Fundamentos para la nueva política exterior Argentina. Buenos Aires: Planeta.

Garzón, J., Prieto, G. (2017). Estrategias de inserción económica internacional de Colombia y Brasil: regionalismo cruzado y estrategia de tamaño. En: Flemes, D., Pastrana, E., Carpes, M. (Eds.). Estado y perspectivas de las relaciones colombobrasileñas, (pp. 119-165). Editorial Pontificia Universidad Javeriana.

Gratius, S. (2017). Brazil and the European Union: from liberal inter-regionalism to realist bilateralism. Revista Brasileira de Política Internacional, 61(1), 1-21.

Kourliandsky, J. (2019, janvier 11). L'Amérique Latine réactive la guerre froide. Tribune, IRIS. http://www.iris-france.org/127962-lamerique-latine-reactive-laguerre-froide

Lee, S. (2012). The Evolutionary Dynamics of Institutional Balancing in East Asia. East Asia Institute EAI, Asia Security Initiative. Working Paper 21.

Lee, S. (2016). Institutional Balancing and the Politics of Mega-FTAs in East Asia. Asian Survey, 56(6), 1055-1076.

Lepage, M. (2011). Vers le développement d'une communauté de sécurité pluraliste en Amérique du Sud avec la mise en place de l'Union des nations sud-américaines. Université Laval.

Merke, F. (2015). Neither balance nor bandwagon: South American international society meets Brazil's rising power. International Politics, 52(2), $178-192$

Mijares, V. (2018). Performance of the South American Defense Council Under Autonomy Pressures. Latin American Policy, 9(2), 258-281. 
Mijares, V., Nolte, D. (2018). Regionalismo post-hegemónico en crisis. Foreign Affairs América Latina, 18(3), 105-112.

Nolte, D. (2014). Latin America's New Regional Architecture: A Cooperative or Segmented Regional Governance Complex? EUI Working Paper RSCAS 2014/89.

Nolte, D. (2017, september). Trade: The Undervalued Driver of Regional Integration in Latin America. GIGA Focus Latin America, 5.

Nolte, D. (2018). Costs and Benefits of Overlapping Regional Organizations in Latin America: The Case of the OAS and Unasur. Latin American Politics and Society, 60 , Issue $1,128-153$.

Nolte, D. (2018a). Latin America: crisis of regionalism vs. advancement of economic integration. International Trade Forum, Issue 4, Regional trade, 18-19.

Nolte, D., Wehner, L. (2014). Unasur and Security in South America. In Aris, S., Wenger, A. (Eds.). Regional Organizations and Security: Conceptions and Practices, (pp. 183-202). London: Routledge.

Pape, R. (2005). Soft Balancing against the United States. International Security $30(1), 7-45$.

Pastrana, E. (2016) Colombia's Contestation Strategies Facing the Emergence of Brazil as a Regional Power. In Gardini, L., Tavares, M. (Eds.). Foreign Policy Responses to the Rise of Brazil, (pp. 177-194). Palgrave Macmillan.

Puig, J. C. (1980). Doctrinas internacionales y autonomía latinoamericana. Caracas: Universidad Simón Bolívar.

Radseck, M. (2017). Las relaciones colombo-brasileñas de defensa: panorama actual. En Flemes, D., Pastrana, E., Carpes, M. (Eds.). Estado y perspectivas de las relaciones colombo-brasileñas, (pp. 57-92). Editorial Pontificia Universidad Javeriana.

Riggirozzi, P., Tussie, D. (Eds.). (2012). The Rise of Post-hegemonic Regionalism. The Case of Latin America. Springer.

Sanahuja, J. (2012). Regionalismo post-liberal y multilateralismo en Suramérica: El caso de Unasur. En Serbin et al. (Eds.). El regionalismo "post-liberal” en América Latina y el Caribe, (pp. 19-7220). Anuario de la Integración Regional de América Latina y el Gran Caribe 9, CRIES, Buenos Aires.

Tickner, A. (2007). Intervención por invitación. Claves de la política exterior colombiana y de sus debilidades principales. Revista Colombia Internacional, No. 65 .

Tickner, A. (2016). Exportación de la seguridad y política exterior de Colombia, Friedrich-Ebert-Stiftung, ISSN 2422-0663. 
Tvevad, J. (2014). The Pacific Alliance: Regional integration or fragmentation? European Parlament. Directorate-General for External Policies. Brussels.

Unasur. (2008, diciembre 11). Estatuto del Consejo de Defensa Suramericano. Propuesta de Grupo de trabajo sobre el Consejo de Defensa Suramericano, rubricada en Santiago de Chile.

Valladão, A. (2014). Brazil - Defense without Threat. In Dane, F. (Ed.). Multilateral Security Governance. International Security: a European-South American Dialogue. Konrad-Adenauer-Stiftung, Centro Brasileiro de Relaçôes Internacionais, Rio de Janeiro ISSN 2176-297X, 147-155.

Weiffen, B., Wehner, L., Nolte, D. (2013). Overlapping regional security institutions in South America: The case of OAS and Unasur. International Area Studies Review, 16(4), 370-389 